\title{
TA Treatment of Depression - A Hermeneutic Single-Case Efficacy Design Study - 'Peter'
}

\section{(C) 2012 Mark Widdowson}

\begin{abstract}
Hermeneutic Single-Case Efficacy Design (HSCED) is a systematic case study research method involving the cross-examination of mixed method data to generate both plausible arguments that the client changed due to therapy and alternative explanations. The present study uses HSCED to investigate the outcome of short-term TA psychotherapy with a young man with severe depression. The objective of the research was to investigate the effectiveness of short-term TA therapy for the treatment of depression and to explore and identify key aspects of the TA therapy process and associated factors promoting change amongst effective cases. To enhance rigour and to address potential for researcher allegiance, independent psychotherapy researchers have adjudicated the case and offer a verdict on outcome. The conclusion of the adjudicators is that the client changed considerably-substantially, and that these changes were substantially due to the effect of therapy.
\end{abstract}

The author provides detailed appendices to encourage others to replicate the research and add to the body of knowledge based on the HSCED process.

\section{Key words}

Depression; Hermeneutic-Single Case Efficacy Design; Case Study Research; Transactional Analysis Psychotherapy.

\section{Introduction}

In this article, the author presents the therapy of Peter, a 28 year old man who sought out therapy for the treatment of depression. This article is the first in a series of HSCED studies conducted by the author as part of his doctoral research investigating the process and outcome of TA psychotherapy for the treatment of depression. The objective of the research is to investigate the effectiveness of short-term TA therapy for the treatment of depression and to explore and identify key aspects of the TA therapy process and associated factors promoting change amongst effective cases. Although depression is one of the most common disorders TA psychotherapists see in practice, the author has only been able to identify one piece of research investigating the outcome of a TA therapy group for the treatment of depression (Fetsch and Sprinkle, 1982). Despite this paucity of TA research on depression, various TA authors have offered theoretical perspectives on the treatment of depression (see Widdowson, 2011b for a summary of the TA literature on depression).

It is the author's aim to develop the TA literature and research evidence-base regarding the effectiveness of TA for the treatment of depression, and by presenting examples of case study research, to encourage the TA community, who are experienced at producing detailed case studies, to engage with case study research and contribute to the TA evidence base. The full, rich case record, the affirmative and sceptic cases, and the Judges Opinions are therefore provided as appendices, along with templates for Information for Participating Clients, Informed Consent Agreement, Therapist Session Notes, Therapist Adherence Checklist, and Supervisor Adherence Checklist.

The client has read the case report and given his consent for the report and extracts from the Change Interview to be included in and published in scientific professional journals.

For many years, psychotherapy research has been dominated by Randomised Controlled Trials (RCTs), which have been used to make claims regarding the efficacy of different therapies. Whilst such trials have provided compelling evidence regarding outcomes of therapy and demonstrated that psychotherapy is an effective treatment for psychological problems, the tightly controlled conditions within which they have been conducted have been criticised as bearing little 
resemblance to the realities of the consulting rooms of most therapists. Furthermore, these studies have not been able to adequately capture the complexity of the client and the therapy and have also been criticised as being 'causally empty' (Elliott, 2002) in that they have not been able to provide detailed description as to how the clients changes have come about. Historically, case study research has been dismissed as unscientific, biased and as simply 'anecdotal evidence' (McLeod, 2010). Recent developments in case study research have begun to address these criticisms by putting forward systematic and robust methods for presenting case study research (Fishman, 1999; Elliott, 2001, 2002; Miller, 2004; Iwakabe and Gazzola, 2009; Bohart et al, 2011; McLeod, 2010).

Elliott's Hermeneutic Single-Case Efficacy Design (HSCED) (Elliott, 2001, 2002) is an approach to case study research which is procedurally-defined and systematically incorporates the critical-reflective crossexamination of both qualitative and quantitative data to develop a detailed and plausible argument that a client has changed as a result of therapy (Elliott, 2002; Stephen and Elliott, 2011). Furthermore, HSCED also involves good-faith attempts to developing plausible alternative explanations for the client's changes. Both arguments are critically evaluated and subjected to a quasi-legal interrogation, and judges are invited to make their verdict about the outcome of the case. Within HSCED, the research questions being investigated are:

- "Did the client change substantially over the course of therapy?

- Is this change substantially due to the effect of the therapy?

- What factors (including mediator and moderator variables) may be responsible for the change?" (Stephen and Elliott, 2011; 231)

In this present study, the judges were asked an additional question, which was to provide a verdict classifying the outcome of the case as either good outcome, mixed outcome, or poor outcome.

As HSCED is a systematic case study approach (Iwakabe and Gazzola, 2009; McLeod, 2010), "data (is) ...gathered from multiple sources, such as questionnaires, therapist and observer ratings, and participant interviews, to construct a rich and comprehensive account or case summary, which is then triangulated in order to examine whether different sources of data converge." (Iwakabe and Gazzola, 2009: 602-3).

HSCED was initially developed as a practitionerresearcher model (McLeod, 1999) of research inquiry that would be accessible to single researchers, therapists and trainees wishing to systematically investigate cases for the purposes of research (Elliott, 2002; Stephen and Elliott, 2011). As HSCED has developed, the analysis and cross-examination of evidence is now generally done by a team of researchers and the deliberations of the research team are sent to independent adjudicators who are invited to evaluate the evidence presented by the affirmative and sceptic teams and to give their opinions on the central research questions of client change and the causal role of the therapy in that change' (Stephen and Elliott, 2011: 232).

The credibility of psychotherapy research can be undermined by the potential for researcher bias - that is, researchers who have a particular allegiance to one type of therapy may inadvertently present a positive bias towards that therapy in their findings. In the present study, this has been addressed by inviting two independent psychotherapy researchers to adjudicate and draw expert conclusions regarding the outcome of the case.

\section{Method}

\section{Participants}

Client

Peter was a 28 year old man who lived alone. At the time of entering therapy he was single, and had been unemployed ever since being made redundant two years previously. Peter had been educated to degree level. He had been diagnosed with depression by a psychiatrist five years earlier, and was not on medication, although he had previously had some therapy which had been unsuccessful. Although he reported having a reasonable number of friends and acquaintances, he presented as being fairly socially isolated, seeing people infrequently. Peter had been bullied throughout school and had felt dominated through his childhood by his strict father. Peter's mother died when he was a teenager and he recalled being in shock immediately following his mother's death and being told by various family members that he 'had to be strong and be a man now'. Consequently he has no recollection of any grieving.

He presented for therapy being aware of holding many buried feelings which he felt sure were driving his depression, but feeling unable to access them and feeling disconnected from feelings in general other than a sense of sadness, despair and hopelessness.

Peter was an intelligent, reflective and articulate young man with evidence of strong psychological mindedness with clear and realistic expectations regarding the process of therapy. He appeared motivated to change, and had sought out therapy independently, doing quite careful research to find a therapist in private practice who he felt would have the necessary skills and experience to help him. He travelled for quite some distance to see his therapist, again suggesting that he was well motivated. 
When Peter came for his initial appointment, the therapist's assessment identified that Peter was eligible to participate in the study, meeting DSM-IV (American Psychiatric Association, 1994) criteria for Major Depressive Disorder, and meeting 'caseness' criteria of a CORE (Barkham et al, 2006) score of over 15 and a Beck Depression Inventory-II (Beck et al, 1961; Beck et al, 1996) score of over 16, and that he did not meet any of the exclusion criteria (e.g. psychosis, bipolar disorder, antidepressant medication, or alcohol or drug abuse and was not experiencing domestic violence). The therapist described the study to Peter and gave him an information pack regarding the research to take away and read. Peter contacted the therapist several days later, stating he would like to participate in the research, and he attended for an intake interview where he completed the outcome measures and a consent form. Peter's scores on CORE-OM indicated moderate distress and functional impairment and his BDI-II score indicated severe depression, which was confirmed in clinical interview. Peter also completed a consent form and release of audio recordings form at the end of the therapy, and has given his permission for his case to be used for the purposes of teaching and research, and to be published in professional journals. He was seen in a naturalistic therapy protocol in private practice. The research covered a period of sixteen sessions, although Peter attended a number of maintenance sessions after the research period to consolidate and develop his gains.

\section{Therapist}

The author, a 38 year old British male was the therapist in this case. He is an experienced TA psychotherapist with 15 years of experience, and a former course tutor to the three members of the analysis team. Using a practitioner-researcher model (McLeod, 1999), the therapist engaged in both therapy and research activities in relation to this case, and this had been made transparent to Peter before, during and after the therapy. The author developed the rich case record and participated in developing the affirmative and sceptic cases, as well as contacting and requesting the participation of the judges. The therapist was supervised on this case by an experienced Teaching and Supervising Transactional Analyst on a monthly basis.

\section{Analysis Team}

The analysis team was comprised of three therapists (Katie Banks, Julia McLeod and Cholena Mountain) and the author. The analysis team were all known to the author and were invited to participate in this process on the basis of particular skills the author felt they had which would be useful in conducting the analysis and was partly due to reasons of convenience and ease of recruitment of members of the team. All three members of the analysis team were experienced therapists and have master's degrees in counselling or psychotherapy and two members are internationally accredited as Certified Transactional Analysts (Psychotherapy specialism) (KB and $\mathrm{CM}$ ). One member has a background in law $(\mathrm{KB})$, and another has also has a master's degree in applied psychology and has experience of working in a psychotherapy research clinic and conducting psychotherapy research (JM). The analysis team were given selected reading to familiarise them with the method, and were sent a copy of the rich case record. Each member of the analysis team participated in developing both the affirmative and sceptic cases.

\section{Judges}

The two independent judges were selected on the basis that they were therapists from another modality, and had experience of conducting a HSCED investigation. The judges were recommended to the author by Robert Elliott, the originator of the HSCED approach and neither judge was known to the researcher. The judges were Rachel MacLeod, a counselling psychologist working in the UK National Health Service, who has a doctorate in counselling psychology and a diploma in Person-Centred Counselling and Susan Stephen, a Person-Centred BACP accredited counsellor working in private practice who has a background in law and a masters degree in counselling.

\section{Measures}

In order to build the rich case record, and to compile multiple sources of evidence, Peter completed a number of quantitative and qualitative procedures which are described below. The therapist also completed detailed, structured session notes and an adherence form (see appendices).

\section{Quantitative Outcome Measures}

Two standardised self-report outcome measures were selected to measure target symptoms (Beck Depression Inventory- BDI-II) (Beck et al. 1996) and global distress/ functional impairment (CORE-OM) (Barkham et al., 2006). These were administered before the first session, and at sessions 8 (mid-way through therapy) and 16 (end of therapy). These measures were also administered at the one-month, three-month and sixmonth follow up periods. These measures were evaluated according to clinical significance (client moved into a non-clinical range score) and Reliable Change Index (Jacobson and Truax, 1991) (nonclinically significant change). See table 1 for Reliable Change Index $(\mathrm{RCl})$ values for each measure.

\section{Weekly Outcome Measures}

In order to measure on-going progress, and to facilitate the identification of key therapeutic events which produce significant change, two weekly outcome measures were administered prior to the start of each session. These were CORE-10 (Connell \& Barkham 2007), a ten item shortened version of the CORE-OM which has good correlation with CORE-OM scores and can be used to monitor change. The second measure was the simplified Personal Questionnaire (PQ) (Elliott, et al, 
1999). This is a client-generated measure in which clients specify the problems they are wanting to address in their therapy, and rate their problems according to how distressing they are finding each problem. The $P Q$ was also administered at each of the three follow-up intervals.

\section{Qualitative Outcome Measurement}

Qualitative outcome data was collected one month after the conclusion of the therapy. The client was interviewed using the Change Interview protocol (Elliott, 2001) - a semi-structured qualitative change measure which invites the client to explain how they feel they have changed since starting therapy, how they think these changes came about, what they felt was helpful or hindering in the therapy, and what changes they feel they still need to make. As part of this, the client identifies key changes they have made and indicates using a five-point scale whether they expected these changes, how likely these changes would have been without therapy, and how important they feel these changes to be.

\section{Qualitative Data about Helpful Aspects of Therapy}

In order to gain data regarding specific events or aspects of the therapy the client found useful, the client completed the Helpful Aspects of Therapy (HAT) (Llewelyn, 1988) at the end of each session. The HAT asks the client to describe both the most and least helpful aspects of the therapy session and to rate the helpfulness/ unhelpfulness of the session.

\section{Therapist Notes}

The therapist also completed a structured session notes form at the end of each session. The therapist provided a brief description of the session and key issues, therapy process, the theories and interventions they used and indicated how helpful they felt the session was for the client.

\section{Adherence}

The therapist also completed a twelve-item adherence form at the end of each session, rating the session on a sixpoint scale. The therapist's supervisor also rated the therapist's work using the same form to verify therapist competence and adherence in providing identifiably TA therapy.

\section{HSCED Analysis Procedure}

\section{Affirmative Case}

The affirmative case is built by identifying positive and convincing evidence to support a claim that the client changed and that these changes primarily came about as a result of therapy. In line with HSCED procedure, to make a convincing case that the client changed positively and as a result of therapy, the affirmative case must be built by identifying evidence for at least two of the following:
1. changes in stable problems: client experiences changes in long-standing problems

2. retrospective attribution: client attributes therapy as being the primary cause of their changes

3. outcome to process mapping: 'Content of the post-therapy qualitative or quantitative changes plausibly matches specific events, aspects, or processes within therapy' (Elliott et. al, 2009; 548)

4. event-shift sequences: links between 'client reliable gains' in the $P Q$ scores and 'significant within therapy' events

\section{Sceptic Case}

The sceptic case is the development of a good-faith argument to cast doubt on the affirmative case that the client changed and that these changes are attributable to therapy. It does this by identifying flaws in the argument and presenting alternative explanations that could account for all or most of the change reported. Evidence is collected to support eight possible non-therapy explanations. These are:

\section{Apparent changes are negative or irrelevant}

6. Apparent changes are due to measurement or other statistical error

7. Apparent changes are due to relational factors (the client feeling appreciative of, or expressing their liking of the therapist or an attempt to please the therapist or researcher) (note, this is a term used in the HSCED approach and does not refer to the impact of the therapeutic relationship as a vehicle for change and relates to factors not directly within the therapy process. The reader is invited to notice the different ways that 'relational' is used within this report, which include this criteria, the therapeutic relationship and a relational approach to therapy)

8. Apparent changes are due to the client conforming to cultural or personal expectancies of change in therapy

9. Improvement is due to resolution of a temporary state of distress or natural recovery

10. Improvement is due to extra-therapy factors (such as change in job or personal relationships etc)

11. Improvement is due to biological factors (such as medication or herbal remedies)

12. Improvement is due to effects of being in the research

Once the sceptic case had been presented, the affirmative team developed rebuttals to the sceptic case. The sceptic team then developed further rebuttals to the affirmative rebuttals, thus providing a detailed and balanced argument. 


\section{Adjudication Procedure}

The rich case record and the affirmative and sceptic cases and rebuttals were then sent to the independent judges for adjudication. The judges were asked to examine the evidence and provide their verdict as to whether the case was a clearly good outcome case, a mixed outcome case, or a poor outcome case; to what extent the client had changed and to what extent these changes had been a result of therapy; and to indicate which aspects of the affirmative and sceptic arguments had informed their position. The judges were also asked to comment on what factors in the therapy did they consider to have been helpful and which characteristics about the client contributed to the changes.

\section{Results}

\section{Quantitative Outcome Data}

Quantitative outcome data for Peter can be seen in Table 1. His pre-therapy scores were all well within the clinical range, and substantially above the caseness cut-off for inclusion in this research. Peter's clinical score at point of entry to therapy using CORE-OM was 21.76, indicating moderate levels of distress and functional impairment and his BDI-II score was 35, indicating severe depression. By the end of therapy, Peter had achieved clinically significant change on CORE-OM and $P Q$, and had achieved reliable change on the BDI-II. Peter's gains continued into the follow-up period, and were maintained at levels of clinically significant change.

At the end of each therapy session, Peter completed the HAT form, indicating what had been helpful or hindering in the session. In each session he indicated at least one helpful event and no unhelpful or hindering events. Many of Peter's comments indicated the events he found most helpful were related to emotional processing, insights or new learning. For example:

- In session 11, Peter said the most helpful part of the session had been 'Achieving the goal I had for the session - finding an experiential approach that will let me find a method of coping with emotions. It's inherently good, as it will be useful, and it's satisfying to achieve.' (rated 9 - 'extremely helpful') This appeared to correspond with the therapist's notes which indicated that the session had focused on deconfusion work expressing and processing emotions.

- In session 15, Peter and the therapist focused on identifying and addressing interpersonal problems and his HAT comments from the session were; 'Recognition of a deficiency in my interpersonal skills and the suggestion of a new approach. It gives me a way forward, to express myself with the confidence that I might be understood. An instant - "eureka!" '(rated 9 'extremely helpful')

\section{Qualitative Outcome Data}

In his follow-up Change Interview, Peter was asked to identify the main changes he felt had occurred during therapy. The changes are listed in Table 2. He identified five changes, two of which related to changes in perspective from a negative, pessimistic outlook to a more balanced one and a similar change relating to the development of hope for the future. Another change related to interpersonal changes, and the final change related to increased awareness of negative reinforcing patterns.

\begin{tabular}{|c|c|c|c|}
\hline & Beck Depression Inventory-II & CORE-OM & $\begin{array}{l}\text { Personal Questionnaire } \\
\text { (mean score) }\end{array}$ \\
\hline $\begin{array}{l}\text { Clinical } \\
\text { cut-off }\end{array}$ & 10 & 10 & 3.00 \\
\hline Caseness cut-off & 16 & 15 & 3.50 \\
\hline Reliable Change Index & 5.78 & 4.8 & 0.53 \\
\hline Pre-Therapy & 35 & 21.7 & 5.83 \\
\hline Session 8 & 32 & 20.2 & $4.71(+)$ \\
\hline Session 16 & $20.0(+)$ & $12.9(++)$ & $2.71(++)$ \\
\hline 1 month Follow-up & $10.0(++)$ & $5.2(++)$ & $2.57(++)$ \\
\hline 3 month Follow-up & $130(++)$ & $11.9(++)$ & $2.28(++)$ \\
\hline 6 month Follow-up & $80(++)$ & $50(++)$ & $2.21(++)$ \\
\hline
\end{tabular}

Note: Values in bold italic are within clinical range. + indicates Reliable Change, ++ indicates change to below 'caseness' level. 
Figure 1. Weekly CORE-10 scores

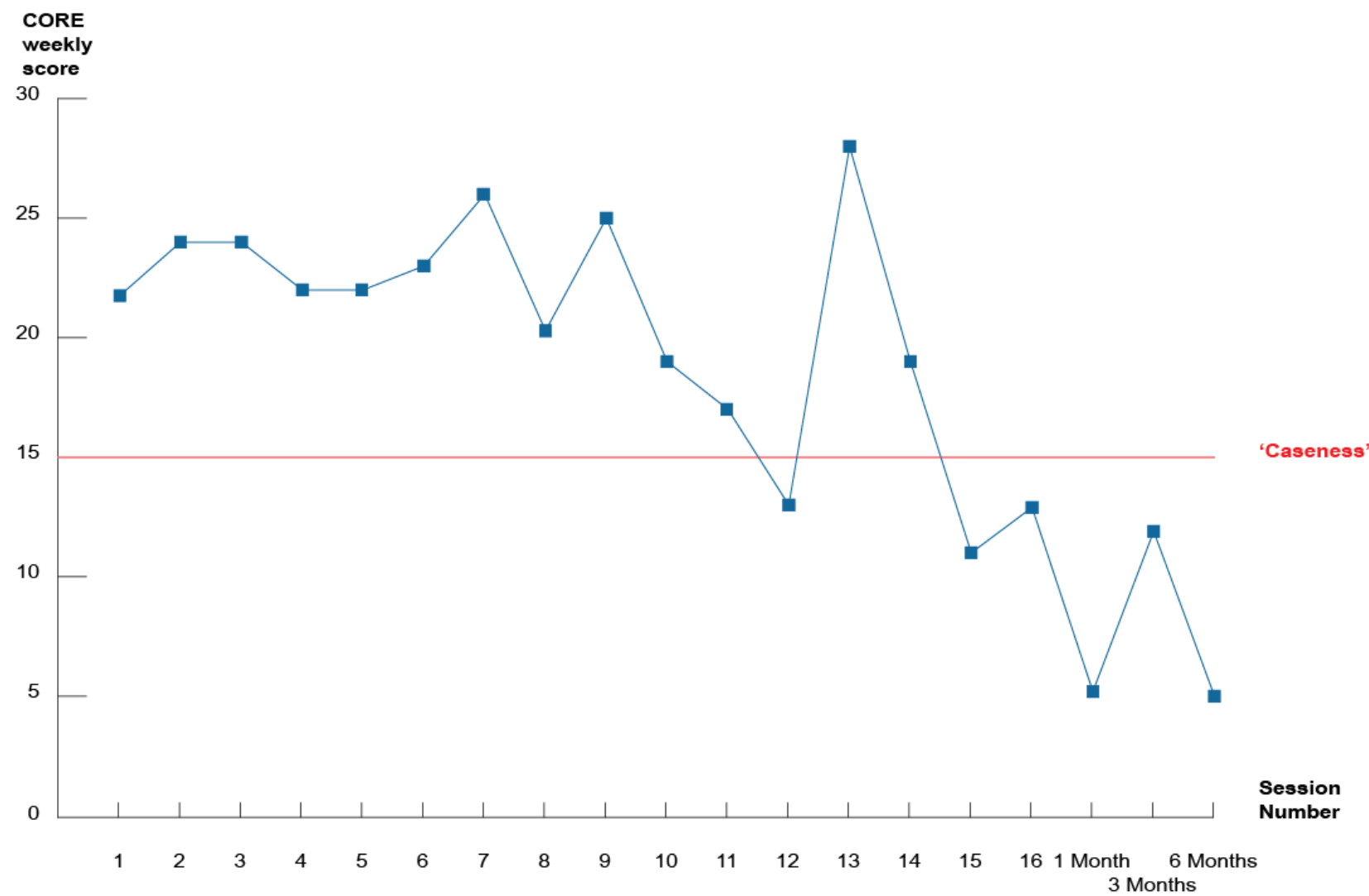

Figure 2. Weekly mean $P Q$ scores

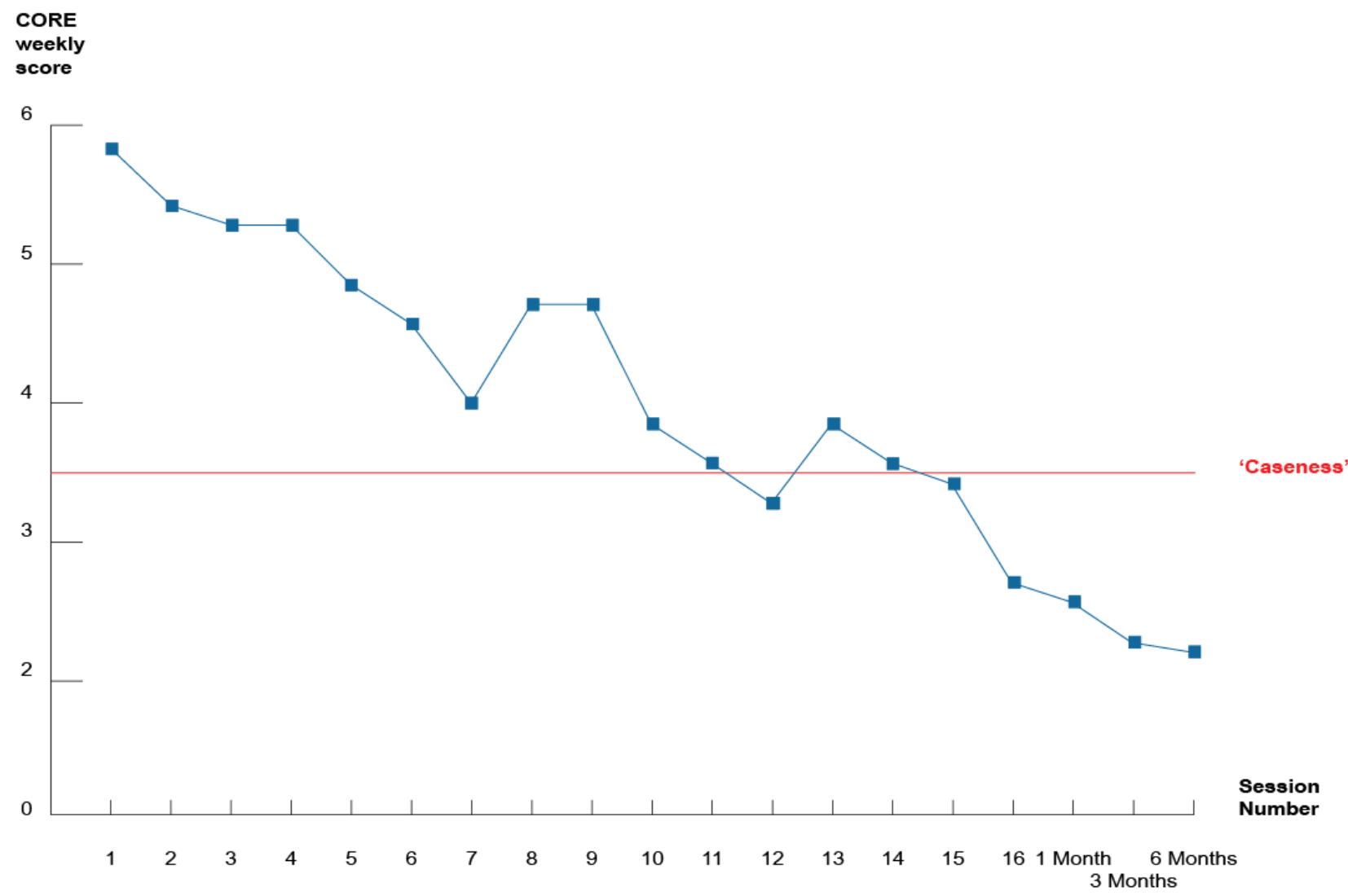


He identified all five changes as both surprising and unlikely to have occurred without therapy. He identified two of these changes as 'extremely important', two as 'very important' and one as 'moderately important'.

Table 2. Peter's changes as identified in post-therapy Change Interview

A shift in perspective from 'life is
$\begin{aligned} & \text { shit' to 'actually, maybe I'm not } \\ & \text { viewing things clearly' }\end{aligned}$

a The rating is on a scale from 1 to 5 ;

$1=$ expected, $3=$ neither, $5=$ surprising

${ }^{\mathrm{b}}$ The rating is on a scale from 1 to 5 ;

$1=$ unlikely, $3=$ neither, $5=$ likely

${ }^{\mathrm{c}}$ The rating is on a scale from 1 to 5 ;

1 =slightly, 3 = moderately, $4=$ very, 5=extremely

Affirmative Case

Below is a summary of the affirmative and sceptic cases and their rebuttals. The full document can be seen in Appendix 2.

The affirmative case presented four lines of argument that Peter had changed substantially, and that these changes had been as a result of therapy. The first argument related to changes in long-standing problems. Peter identified five of his seven problems listed in his $P Q$ as of more than 10 years in duration and that he had achieved global reliable change on all outcome measures, clinically significant change in two measures by the end of therapy, and clinically significant change on all three measures by the end of the follow-up period. Peter's retrospective attribution during his posttherapy Change Interview of the changes being unlikely to have come about without therapy was cited as another source of evidence. The affirmative case argued that Peter's comments in his HAT forms were consistent with TA therapy and the account of the therapy as described by the therapist and that direct and plausible correspondence was found between these events and the overall changes Peter identified in his Change Interview.

\section{Sceptic Case}

The sceptic case presented three main alternative arguments to the affirmative case. These were that although Peter had demonstrated improvement on quantitative outcome measures, his BDI-II scores were still within the clinical range at the end of therapy, as was one of his $P Q$ scores. They also identified that in the second follow-up, Peter reported deterioration on both CORE-OM and BDI-II scores to within clinical levels of distress, suggesting that Peter's changes had not been maintained. The sceptic case also considered that due to Peter's positive description of the therapy and the therapist in his Change Interview, it was possible that (social) relational factors were influencing his report, and that despite his positive descriptions, he had not made any significant life changes during the course of therapy.

\section{Affirmative Rebuttal}

The affirmative rebuttal included the argument that even though there had been some deterioration in Peter at follow-up two, his $P Q$ scores had shown improvement indicating that his problems had not returned. It was suggested that as all scores improved at follow-up three, that the deterioration represented a period of temporary distress and that it was possible that Peter had developed sufficient internal resources and had experienced sufficient personal change during the course of his therapy to enable him to overcome this period of distress effectively without experiencing relapse.

Sceptic arguments of relational factors were countered by the affirmative rebuttal noting that the narrative of the case study suggests that at several points the client and therapist experienced difficulties and relationship ruptures which appeared to have been successfully resolved, and that it is perhaps only to be expected that a client who had been through such rupture repairs would emphasise the relational skills of their therapist.

Similarly, sceptic suggestions that the work was tinged by an overly positive glow were not supported by statements by the client that he felt he still had work to do, and felt that these statements added balance and credibility to claims that the therapy was effective and appropriate to the client's needs.

Finally the affirmative rebuttal noted that even though Peter had not made any substantial life changes, he had made a number of internal changes, and that his case included sufficient evidence of behavioural change. It was also noted that given Peter's circumstances (unemployment, being a part-time carer) it was unrealistic to expect substantial life changes. 


\section{Sceptic Rebuttal}

The sceptic rebuttal focused on the argument that at the end of therapy, the client experienced a temporary feeling of well-being, which arose from regular contact with his therapist, but did not exhibit any substantial shift in his relationships with other people, or in his everyday life as a whole. As a result, as the meetings with the therapist tailed off, his symptoms gradually returned. Furthermore, that although in the third (six month) follow-up measurements Peter demonstrated an improvement in his scores from those at the second (three month) follow-up, with reliable change occurring on his CORE scores, no further information is provided to account for either the increase in scores at the threemonth follow-up or the reduction in scores at the sixmonth follow-up. The argument was put forward that this fluctuation may indicate that the impact of extratherapy factors on Peter's symptoms is greater than has been indicated previously, and/or that his symptoms are more reactive and responsive to external stressors than suggested in the case report.

\section{Adjudication}

Each judge independently produced their opinions and ratings of the case. Their individual conclusions are presented in Table 3. A median score has been given to represent a balance of the two judge's conclusions. To summarise, the judges concluded that Peter had experienced clinically significant changes, although had not fully resolved his problems, and that these changes were substantially due to therapy.

Summary of opinions regarding how the judges would categorise this case

(Clearly good outcome - problem completely solved, Mixed outcome - problem not completely solved, Negative/ Poor Outcome)

The judges considered that data from the quantitative change measures (CORE, BDI-II and $P Q$ ) provided evidence of clinically significant changes in both client identified problems (PQ), global distress and functional impairment (CORE) and target symptoms (BDIII).Paired with Peter's retrospective account from his Change Interview, this provided convincing evidence that positive change had taken place and was evidence to suggest this had been an effective therapy. They noted that Peter identified a number of problems of a long-standing nature which had achieved clinically significant change as indicated by PQ scores by the end of the therapy.

Judge B commented that Peter had clearly had a significant experience and had 'gained a major increase in his self-awareness and self-understanding, he has experienced a genuine honest and accepting relationship in which difficulties have been discussed and survived. He appears to have maintained the progress that he achieved (as measured by CORE etc) six months after the end of therapy. However he also recognised that what he has gained in this therapy is a foundation for future work and identified further areas of his experience that he wished to explore.' However, the judges noted that the evidence from the case indicated that Peter had not completely resolved all of his problems, and so were not able to state that the outcome was completely positive and therefore concluded that the outcome of the case was 'mixed outcome'.

Summary of opinions regarding the extent to which the client had changed

The judges concluded that Peter had changed considerably-substantially over the course of therapy, highlighting data from quantitative outcome measures and the Change Interview as providing convincing evidence that Peter had achieved clinically significant change. Judge A viewed the client's comments in his Change Interview as being wholly positive, which led her to be sceptical about the extent of his changes, although Judge $B$ considered that Peter's Change Interview offered a more balanced perspective on his change process. Both judges commented that they would have liked more information on extra-therapy events and changes Peter had made.

Judge A commented that although Peter stated in both his HAT forms and the Change Interview that the therapy was helpful, he did not provide specific examples or details of the actual therapy processes which produced these changes. However she did concede that 'Perhaps it is unrealistic to expect that an individual who is not a therapist should, without any real prompting, be able to offer accurate, detail-rich and precise accounts of moments within therapy where change occurred'.

Summary of opinions as to whether the changes were due to the therapy

The judges noted that Peter appeared to be a motivated client with a readiness to engage which enabled him to make good use of the therapy. Both judges commented that motivation alone would be insufficient to produce change of this magnitude. One judge noted that as there were no significant changes in Peter's life during the course of therapy that it was 'logical to deduce... that therapy was the main agent of change'. The second judge noted that 'the relational approach that the therapist adopted within this work was a significant factor in enabling Peter to participate fully and effectively in the therapy'.

\section{Mediator factors}

The judges were asked to comment on which therapy processes appeared to have been helpful to the client. Both judges agreed that from Peter's account it was clear that his experience of the therapist as empathic, genuine, honest, accepting and caring, and the therapist's willingness to become emotionally engaged with him on a 'human level', had been highly significant. 


\begin{tabular}{|c|c|c|c|}
\hline & & \multirow[b]{2}{*}{ Judge B } & \multirow{2}{*}{ Median } \\
\hline & Judge A & & \\
\hline $\begin{array}{l}\text { 1. How would } \\
\text { you categorise } \\
\text { this case? }\end{array}$ & & & \\
\hline $\begin{array}{l}\text { How certain are } \\
\text { you? }\end{array}$ & & & \\
\hline $\begin{array}{l}\text { 1a. Clearly good } \\
\text { outcome } \\
\text { (problem } \\
\text { completely } \\
\text { solved) }\end{array}$ & $40 \%$ & $60 \%$ & $50 \%$ \\
\hline $\begin{array}{l}\text { 1b. Mixed } \\
\text { Outcome } \\
\text { (problem not } \\
\text { completely } \\
\text { solved) }\end{array}$ & $80 \%$ & $100 \%$ & $90 \%$ \\
\hline $\begin{array}{l}\text { 1c.Negative/ } \\
\text { Poor Outcome }\end{array}$ & $0 \%$ & $0 \%$ & $0 \%$ \\
\hline $\begin{array}{l}\text { 2. To what } \\
\text { extent did the } \\
\text { client change } \\
\text { over the course } \\
\text { of therapy? }\end{array}$ & $\begin{array}{l}60 \% \\
\text { Considerably }\end{array}$ & $\begin{array}{l}80 \% \\
\text { Substantially }\end{array}$ & $\begin{array}{l}70 \% \\
\text { Considerably- } \\
\text { Substantially }\end{array}$ \\
\hline $\begin{array}{l}\text { 2a. How certain } \\
\text { are you? }\end{array}$ & $\begin{array}{l}60 \% \\
\text { Considerably }\end{array}$ & $\begin{array}{l}80 \% \\
\text { Substantially }\end{array}$ & $\begin{array}{l}70 \% \\
\text { Considerably- } \\
\text { Substantially }\end{array}$ \\
\hline $\begin{array}{l}\text { 3. To what } \\
\text { extent is this } \\
\text { change due to } \\
\text { therapy? }\end{array}$ & $\begin{array}{l}80 \% \\
\text { Substantially }\end{array}$ & $\begin{array}{l}80 \% \\
\text { Substantially }\end{array}$ & $\begin{array}{l}80 \% \\
\text { Substantially }\end{array}$ \\
\hline $\begin{array}{l}\text { 3a. How certain } \\
\text { are you? }\end{array}$ & $\begin{array}{l}80 \% \\
\text { Substantially }\end{array}$ & $\begin{array}{l}80 \% \\
\text { Substantially }\end{array}$ & $\begin{array}{l}80 \% \\
\text { Substantially }\end{array}$ \\
\hline
\end{tabular}

One judge expressed their disappointment that Peter had not provided specific examples of interventions or events that had occurred in therapy. Nevertheless, both judges noted that the therapist's willingness to provide theoretical understanding to Peter had been helpful in developing his understanding of himself and his relationships, with one judge observing that this had clearly been done skilfully as it did not appear to negatively impact Peter's relationship with his therapist, despite Peter emphasising in his change interview that he had a very low tolerance for 'feeling managed'.

\section{Moderator factors}

The judges were also asked to comment on which characteristics or personal resources of the client enabled him to make the best use of his therapy. Both judges agreed that Peter's investment in the process, his motivation and his desire to seek out the right therapy and therapist for him and his belief in therapy and his determination to overcome his initial discomfort had clearly enabled Peter to make the best possible use of his therapy.

\section{Discussion}

This case raises interesting questions regarding what constitutes valid and convincing evidence, and the importance of accounting for the client context. It also provides data which support the objective of the research which was to investigate the process and outcome of short-term TA psychotherapy for the treatment of depression, by identifying key factors which impact on the process and a clear statement of outcome. With regard to relevant process factors, this study also verifies several aspects of previous research regarding factors which positively influence therapy outcome, namely: the importance of client motivation, willingness and ability to engage; the importance of a good match between therapist, therapy approach and the client; and the centrality of the therapeutic relationship in effecting change (Norcross, 2002).

This case also provides initial evidence that short-term TA therapy can be effective for the treatment of depression, even at quite high levels of severity.

Although there was some difference in the judge's verdicts regarding the magnitude of the client's change, they were in agreement that the client clearly had changed positively and that therapy was highly likely to have been the primary causative factor in these changes.

What is missing from this case is a detailed understanding of the processes and specific mechanisms of change. Future studies are warranted to explore these mechanisms and it is anticipated that the other cases in this case series will provide such data and facilitate the development and refinement of TA theory and practice for the treatment of depression.

\section{Limitations}

One limitation of this present study is the potential impact of the author being both the therapist and a researcher. Even though a critical-reflective stance was used in developing the case report, and this work has been checked by the author's research supervisors and clinical supervisors, it is possible that some inadvertent bias may have crept into the report.

Furthermore, as the author was also a former tutor of the three members of the analysis team, and participated in the analysis in order to facilitate the process, this may also have influenced the findings. In order to reduce this possibility, members of the analysis team were not consciously aware that the researcher was the therapist in this case. In the rich case record, the therapist's identity was obscured and this appeared to have been successful as in the report of one member of the analysis team they had assumed the therapist was female. 
It is hoped that the use of independent judges, who were not made aware of the therapist's identity, has mitigated against any potential bias. As only two judges were used in this study, where there was a difference in opinion, a median verdict was selected. It is possible that a third judge would have carried the balance in one direction resulting in a majority verdict, thus influencing the conclusions regarding outcome in this case.

It is unfortunate that the Change Interview did not include a more rigorous exploration of extra-therapy factors with the client, in particular in the period after concluding therapy to provide evidence regarding whether the client's continued improvement was a continuation and building upon changes made in therapy or whether these were to do with extra-therapy factors.

\section{Conclusion}

The conclusions of the judges in this case are that Peter changed considerably-substantially, although not all of his problems were resolved, and that these changes were substantially due to therapy. Although Peter achieved clinically significant change on all quantitative measures, there were reasons to believe that he had not fully resolved all aspects of his depression within 16 weeks of therapy. In line with existing psychotherapy research into common factors, the therapeutic relationship was identified as being a primary cause of change. Peter identified a number of key changes that had come about as a result of his therapy - including changes in his perspective, interpersonal changes and the development of hope for his future. Although this single case cannot be used as clear evidence that TA therapy is effective for the treatment of depression, it nevertheless provides evidence that TA therapy has been effective in the treatment of depression for a man who had chronic, severe depression. With sufficient replication of these findings, it is possible that claims that TA therapy is effective for depression can be made. Furthermore, the present case has demonstrated that outcomes of therapy can be ambiguous, and that it is not always possible to make clear-cut and definitive statements of clear cause-effect relationships between therapy and outcome due to the complexity of factors present in each case.

\section{Future Research Considerations}

It is possible to meet criteria for being considered to be an established, efficacious, empirically supported therapy solely through the use of case study research. As few as nine published cases of positive replication of findings of outcomes of a particular therapy for a specific disorder are needed to meet these criteria (Chambless and Hollon, 1998).

The TA community already has expertise in producing detailed case studies as part of the international certification process and the small-scale nature of such research means it is feasible to rapidly accumulate positive evidence demonstrating TA's effectiveness for the treatment of depression, or any other disorder. Because case study research accounts for the context of the client and the therapy and a range of factors which impact on the case outcome, and incorporates both quantitative and qualitative data, it is an approach which is highly congruent with and relevant to the philosophy and approach of TA therapy (see Widdowson, 2011a).

The team-based approach of HSCED is a rigorous process that can be used to demonstrate TA as an effective therapeutic approach. Small, independent teams of perhaps three TA therapists could replicate the methodology used in this article to develop the evidence base of TA psychotherapy. Each published case or case series (with, say, three cases) would substantially add to the evidence base of TA and provide a balance to the limitations in this present case.

Mark Widdowson, Teaching and Supervising Transactional Analyst (Psychotherapy), Associate Director, The Berne Institute, Ph D student, University of Leicester, can be contacted on: mark.widdowson1@btopenworld.com

\section{References}

American Psychiatric Association (Ed.) (1994) Diagnostic and Statistical Manual of Mental Disorders-fourth edition. Washington, DC: American Psychiatric Association

Beck, A.T., Ward, C.H., Mendelssohn, M.J. and Erbaugh J. (1961) 'An inventory for measuring depression'. Archives of General Psychiatry, 4:561-571

Beck, A.T., Steer, R.A., and Brown, G.K. (1996) Manual for the Beck Depression Inventory-II. San Antonio, TX: Psychological Corporation

Barkham, M., Mellor-Clark, J., Connell, J., and Cahill, J. (2006). A core approach to practice-based evidence: a brief history of the origins and applications of the CORE-OM and CORE system. Counselling and Psychotherapy Research, 6(1): 3-15.

Beck, A.T., Steer, R.A., Brown, G.K. (1996) Manual for Beck Depression Inventory II (BDI-II). San Antonio, TX: Psychology Corporation

Bohart, A.C., Tallman, K.L., Byock, G. and Mackrill, T. (2011) 'The "Research Jury" Method: The Application of the Jury Trial Model to Evaluating the 101 Validity of Descriptive and Causal Statements about Psychotherapy Process and Outcome'. Pragmatic Case Studies in Psychotherapy, 7(1): 101-144 (article available from: http://pcsp.libraries.rutgers.edu) Downloaded 4th March, 2011

Chambless, D.L. and Hollon, S.D. (1998) 'Defining Empirically Supported Therapies'. Journal of Consulting and Clinical Psychology, 66(1): 7-18 
Connell, J. \& Barkham, M. (2007). CORE-10 User Manual, Version 1.1. CORE System Trust \& CORE Information Management Systems Ltd

Elliott, R. (2001). Hermeneutic single case efficacy design (HSCED): An overview. In K.J. Schneider, J.F.T. Bugental \& J.F. Fraser (eds.), Handbook of Humanistic Psychology (pp315-324), Thousand Oaks, CA: Sage.

Elliott, R. (2002) 'Hermeneutic Single-Case Efficacy Design'. Psychotherapy Research, 12(1): 1-21

Elliott, R., Mack, C., \& Shapiro, D. (1999). Simplified Personal Questionnaire Procedure. (On-line). Available: http://www.experiential-researchers.org/instruments/elliott/ PQ Procedure.doc Downloaded 25 January 2012

Elliott, R., Partyka, R., Alperin, R., Dobrenski, R., Wagner, J., Messer, S.B.,Watson, J.C. and Castonguay, L.G.(2009) 'An adjudicated hermeneutic single-case efficacy design study of experiential therapy for panic/phobia'. Psychotherapy

Research, 19(4-5): 543-557

Fetsch, R. J., and Sprinkle, R. L. (1982) 'Stroking treatment effects on depressed males'. Transactional Analysis Journal, 12(3): 213-7.

Fishman, D.B. (1999) The Case for a Pragmatic Psychology. New York, NY: University Press.

Iwakabe, S. \& Gazzola, N. (2009) 'From single-case studies to practice-based knowledge: aggregating and synthesizing case studies'. Psychotherapy Research, 19, 601-611
Jacobson, N. S., \& Truax, P. (1991). 'Clinical significance: A statistical approach to defining meaningful change in psychotherapy research'. Journal of Consulting and Clinical Psychology, 59: 12-19

Llewelyn, S. (1988) 'Psychological therapy as viewed by clients and therapists'. British Journal of Clinical Psychology, 27, 223-238.

McLeod, J. (1999) Practitioner Research in Counselling. London: Sage

McLeod, J. (2010). Case Study Research in Counselling and Psychotherapy. London: Sage

Miller, R.B. (2004). Facing human suffering: Psychology and psychotherapy as moral engagement. Washington, DC: American Psychological Association.

Stephen, S and Elliott, R. (2011) 'Developing the Adjudicated Case Study Method'. Pragmatic Case Studies in Psychotherapy, 7(1): 230-241 (article available at: http://pcsp.libraries.rutgers.edu) Downloaded 4th March 2011

Widdowson, M (2011a) 'Case Study Methodology'. International Journal of Transactional Analysis Research, 2(1): $25-34$

Widdowson, M. (2011b) 'Depression: Diagnosis, Sub-types, Patterns of Recovery and Psychotherapeutic Models - a Literature Review.' Transactional Analysis Journal, 41(3) 